\title{
Cellulose Fibers (dominant protecting means/tool) against COVID-19. Facemasks Pros, Cons, and Challenges
}

\author{
Michal Jablonský, ${ }^{\mathrm{a}}$ Ján Homola, ${ }^{\mathrm{b}}$ Michal Masaryk, ${ }^{\mathrm{c}}$ Monika Sláviková, ${ }^{\mathrm{d}}$ \\ Mária Homolová, ${ }^{\mathrm{b}}$ Alexandra Bražinová, ${ }^{\mathrm{e}}$ and Svetozár Katuščák ${ }^{\mathrm{a}, *}$ \\ Cellulose materials and related bioresources have been the first-line tools \\ of defense of human health against COVID-19. The alfa cellulose, wood \\ cellulose, and multilayer composite face masks have been used by \\ billions, simultaneously with millions of tons of cellulosic bioresources- \\ based medical specialty, hygiene, and packaging products used to deal \\ with the global disaster. This editorial considers recently available facts \\ and disputes some statements that have appeared in the media during the \\ year 2020 concerning properties and the risks of the masks. According to \\ recent findings, the carbon dioxide concentration increases by 2.3 to 4.3 \\ times inside of the mask, compared to ambient air, and therefore we \\ suppose that there will be also a concentration increase of larger chemical \\ compounds, toxins, volatile organic compounds (VOC), and particles. \\ These quantities should be measured, and the data used in further \\ research aimed at quality improvement.
}

Keywords: Cellulose fibers; COVID-19; Masks; Facts

Contact information: a: Institute of Natural and Synthetic Polymers, STU, Radlinského 9, Bratislava, Slovakia; b: Homola Furniture Group, Kopcianska 2442/82, 85101 Bratislava; c: Institute of Energy Machinery, Námestie slobody 17, 81231 Bratislava; d: Institute of Virology, Biomedical Research Center, Slovak Academy of Sciences, Dúbravská cesta 9, 84505, Bratislava; e: Institute of Epidemiology, Comenius University, Špitálska 24, 81372 Bratislava; *Corresponding author: svetozar.katuscak@stuba.sk

\section{Introduction}

Cellulosic materials have been the first-line tools of defense of human health against COVID-19. Most face masks use filtration layers of cellulose and composite fibers. Examples include alpha cellulose-containing masks, breathable wool masks, and the papercontaining surgical masks (Matuschek et al. 2020), which have become an integral part of life today. Wearing a face mask significantly reduces the burden on society of COVID-19. In combination with social distancing, this effect is further increased (Chu et al. 2020; Ming et al. 2020)

\section{Data on minuses, risks}

It is known that facemasks make breathing more difficult (Kyung et al. 2020). The reduced work efficiency and other physiological/physiological problems can be indicated during long-term wearing of the mask. The adverse effect of prolonged mask use can include headaches, skin breakdown, acne, and impaired cognition (Rosner 2020). Therefore, more permeable masks are recommended for physical activities, work, and exercising (Lazzarino et al. 2020).

Comparison of the most recent findings from various authors during 2020 has led us to be concerned about the permeability and breathability of the face masks in terms of 
the chemical compounds in the breathing exhalation and inhalation zone. Contrary to previous statements and claims of some institutional authorities (BBC 2020) and authors (Forster 2020; Shapiro 2020), data from GC-MS analysis (Geiss 2020) showed that carbon dioxide concentration $(c \mathrm{CO} 2)$ increases by 2.3 to 4.3 times in the breathing zone (inside of the mask, compared to ambient air). Because the $\mathrm{CO}_{2}$ molecule is small, this range probably can be used as a conservative estimate for larger chemical compounds, such as VOC, toxins, particles, and aerosols, as well. The $c \mathrm{CO} 2$ value ranged from 500 to $900 \mathrm{ppm}$ while not wearing a face mask, and it ranged from 2,150 \pm 192 to 2,875 \pm 323 ppm while wearing a surgical mask and a cloth mask.

We think that the reason for the misleading claims (BBC 2020; Forster 2020; Shapiro 2020) and misunderstanding was the reduction of the dimensionality of the real multidimensional complex phenomena of the chemical compounds behavior in the breathing zone of the face mask to one dimension only - the size. They compared the size of the $\mathrm{CO}_{2}$ molecule with the face mask openings. The openings (such as 19,290 nm; Leonas et al. 2003) are 5845 times larger than $\mathrm{CO}_{2}(0.33 \mathrm{~nm}$; Aguilar-Armenta et al. 2003). The authors did not take into account meaningful dimensions of the phenomena such as inhaling, exhaling, kinetic quantities, adsorption, chemisorption, the existence and function of the aerodynamic resistance for the $\mathrm{CO}_{2}$ and any fluids (and solids), of the filter bed; therefore, they claimed that the $c \mathrm{CO} 2$ increase inside the face mask should not be possible, as the "carbon dioxide molecules are simply too small to be controlled by the majority of mask materials and simply pass right through" (Forster 2020).

Some estimates can be made based on the reported $c \mathrm{CO} 2$ increases inside of the mask, compared to ambient air (Geiss 2020). This can be used to predict the concentrations of the 200 to 3,000 other chemical compounds that have been identified in various studies (Phillips et al. 1999; Filipiak et al. 2012). These are mainly the VOCs most prevalent in exhaled air in human breath, which include toluene, p-xylene, benzene, ethylbenzene, acetone, styrene, and other 42 chemical compounds (Phillips et al. 2013). Exhaled breath condensate, captured by a mask, also contains endogenous compounds (e.g. octacosanoic acid; methyl hexadecanoate; dodecyl hexadecanoate) and human cytokines (e.g. IL-1 $\beta$, IL2) (Wallace et al. 2019).

\section{Questions for Future Research}

Questions can be as important as answers for any successful research involving analytical and process technology development (Hubbe et al. 2017). The questions, hypotheses, and answers concerning the VOC and the air quality can lead us to new questions (Bartekova and Katuscak 2006; Katuscak and Gfeller 2006).

- What is the concentration change of the most important air components in the breathing zone under the face mask in comparison with respirators and other means of human face protection? What are their health effects? By what factor does air within a face mask become diluted during a typical intake of breath?

- How much of the chemical compounds get back into the lungs?

- We propose to apply the Geiss method (Geiss 2020) for measurement the concentration change of hundreds of the VOCs, TVOC, MVOC (microbial VOC), and particles, under the mask in comparison to the surrounding air and clean air reference.

- What is the effect of the air component size, the kind and filter modification of the face protectors on the concentration change of the air component and the pressure drop? 


\section{Conclusion}

Important questions concerning the wearing of cellulose and composite facemasks still need to be answered. The concentration increase of $\mathrm{CO}_{2}$ under the face masks is a demonstrated fact. As a follow-up, it would be important to quantify and minimize the concentration increase of the chemical compounds, namely VOC, toxins, and particles, in the breathing zone under the masks, and further improve the protective health effects of the facemasks. Knowledge needs to be improved regarding the specific permeability of various types of cellulose materials and face protectors for particular toxic, carcinogenic or health promoting chemicals as a base for continuing improvement of facemasks. Recommendations: Increase the simultaneous protection of yourself and others by FFP2 + grade; Compare the concentration changes inside of the basic FFP2 + grades masks and protectors. Such research is useful for human health, for correct use of cellulose and composite fibrous materials, for the present stage of the COVID-19 pandemics, as well as for potential future global disasters.

\section{References}

Aguilar-Armenta, G., Patiño-Iglesias, M. E., and Leyva-Ramos, R. (2003). “Adsorption kinetic behaviour of pure $\mathrm{CO}_{2}, \mathrm{~N}_{2}$ and $\mathrm{CH}_{4}$ in natural clinoptilolite at different temperatures," Adsorption Science \& Technology 21(1), 81-91. DOI: $10.1260 / 02636170360699831$

Bartekova, A., Katuscak, S. (2006). "VOC. emissions of volatile organic compounds (in Slovak)," STU, Bratislava. ISBN 80-227-2459-9.

BBC. 2020. Available online: https://www.bbc.com/news/53108405, accessed 17 December 2020.

Chua, M.H., Cheng, W., Goh, S.S., Kong, J., Li, B., Lim, J.Y., Mao, L., Wang, S., Xue, K., Yang, L. and Ye, E. (2020) "Face masks in the new COVID-19 normal: Materials, testing, and perspectives," Research 2020, ID 7286735. DOI: 10.34133/2020/7286735

Chu, D. K., Akl, E. A., Duda, S., Solo, K., Yaacoub, S., Schünemann, H. J., El-harakeh, A., Bognanni, A., Lotfi, T., Loeb, M., and Hajizadeh, A. (2020). "Physical distancing, face masks, and eye protection to prevent person-to-person transmission of SARSCoV-2 and COVID-19: A systematic review and meta-analysis," The Lancet 395, 1973-1987. DOI: 10.1016/S0140-6736(20)31142-9

Filipiak, W., Ruzsanyi, V., Mochalski, P., Filipiak, A., Bajtarevic, A., Ager, C., Denz, H., Hilbe, W., Jamnig, H., Hackl, M., and Dzien, A. (2012). "Dependence of exhaled breath composition on exogenous factors, smoking habits and exposure to air pollutants," J. Breath. Res. 6(3), 036008. DOI: 10.1088/1752-7155/6/3/036008.

Forster, V. (2020). "Wearing a mask to reduce the spread of coronavirus will not give you carbon dioxide poisoning," Forbes. Available online: https://www.forbes.com/sites/victoriaforster/2020/05/12/wearing-a-mask-to-reducethe-spread-of-coronavirus-will-not-give-you-carbon-dioxidepoisoning/?sh=31a9de4917f5, accessed 17 December 2020.

Geiss, O. (2020). "Effect of wearing face masks on the carbon dioxide concentration in the breathing zone," Aerosol Air Qual. Res. DOI: 10.4209/aaqr.2020.07.0403

Hubbe, M. A., Smith, R. D., Zou, X., Katuscak, S., Potthast, A., and Ahn, K. (2017). "Deacidification of acidic books and paper by means of non-aqueous dispersions of alkaline particles: A review focusing on completeness of the reaction," BioResources 12(2), 4410-4477. DOI: 10.15376/biores.12.2.Acidic_Books_Hubbe 
Katuscak, S. (2006). "EQ. Environmental quality of materials and products (in Slovak)," $2^{\text {nd }}$ Ed., E\&LT Bratislava, Slovak University of Technology, Bratislava. ISBN 80227-2458-0.

Katuscak, S., and Gfeller, B. (2006). "Biocompatibility and Habitability of Materials and Products," $3^{\text {rd }}$ Ed., Ekorex SK, Bratislava, ISBN 80-88812-17-8.

Kyung, S. Y., Kim, Y., Hwang, H., Park, J. W., and Jeong, S. H. (2020). "Risks of N95 face mask use in subjects with COPD," Respir Care 65, 658-664. 10.4187/respcare.06713 31992666.

Lazzarino, A. I., Steptoe, A., Hamer, M., and Michie, S. (2020). “Covid-19: Important potential side effects of wearing face masks that we should bear in mind," The BMJ 369, m2003. DOI: 10.1136/bmj.m2003.

Leonas, K. K., Jones, C. R., and Hall, D. (2003). "The relationship of fabric properties and bacterial filtration efficiency for selected surgical face masks," J. Text. Apparel Technol. Manag. 78, pp. 1-8.

Liu, K., Wang, H., Liu, H., Nie, S., Du, H., and Si, C. (2020). "COVID-19: Challenges and perspectives for the pulp and paper industry worldwide," BioResources 15(3), 4638-4641. DOI: 10.15376/biores.15.3.4638-4641

Matuschek, C., Moll, F., Fangerau, H., Fischer, J. C., Zänker, K., van Griensven, M., Schneider, M., Kindgen-Milles, D., Knoefel, W.T., Lichtenberg, A., and Tamaskovics, B. (2020). "Face masks: Benefits and risks during the COVID-19 crisis," Eur. J. Med. Res. 25, 3. DOI: 10.1186/s40001-020-00430-5

Phillips, M., Cataneo, R. N., Chaturvedi, A., Kaplan, P. D., Libardoni, M., Mundada, M., Patel, U., and Zhang, X. (2013). "Detection of an extended human volatome with comprehensive two-dimensional gas chromatography time-of-flight mass spectrometry," PloS one 8(9), e75274. DOI: 10.1371/journal.pone.0075274

Phillips, M., Herrera, J., Krishnan, S., Zain, M., Greenberg, J., and Cataneo, R. N. (1999). "Variation in volatile organic compounds in the breath of normal humans", $J$ Chromatogr B Biomed Sci Appl 729(1-2), 75-88. DOI: 10.1016/s03784347(99)00127-9.

Rosner, E. (2020). "Adverse effects of prolonged mask use among healthcare professionals during COVID-19?" J. Infect. Dis. Epidemiol. 6, 130. DOI: $10.23937 / 2474-3658 / 1510130$

Shapiro, N. (2020). "Study: Masks do not increase carbon dioxide levels in patients with chronic lung disease," Forbes. Available online: https://www.forbes.com/sites/ninashapiro/2020/10/12/study-masks-do-not-increasecarbon-dioxide-levels-in-patients-with-chronic-lung-disease/?sh=43b6460f6388, accessed 17 December 2020.

Wallace, M. A. G., Pleil, J. D., and Madden, M. C. (2019). "Identifying organic compounds in exhaled breath aerosol: non-invasive sampling from respirator surfaces and disposable hospital masks," J. Aerosol Sci. 137, 105444. DOI: 10.1016/j.jaerosci.2019.105444. 